City University of New York (CUNY) CUNY Academic Works

\title{
Making Translinguality and Transnationality Visible
}

Heather M. Robinson

CUNY York College

Jonathan Hall

CUNY York College

Nela Navarro

Rutgers University - New Brunswick/Piscataway

\section{How does access to this work benefit you? Let us know!}

More information about this work at: https://academicworks.cuny.edu/yc_pubs/281

Discover additional works at: https://academicworks.cuny.edu

This work is made publicly available by the City University of New York (CUNY).

Contact: AcademicWorks@cuny.edu 


\title{
Chapter One Making Translinguality and Transnationality Visible
}

\author{
Do you even know how smart I am in Spanish? \\ - Gloria (Sofia Vergara) in TV's Modern Family
}

Ask the students. That is the simple premise that underlies the several related studies that are discussed in these pages. All of them focus on college students on U.S. campuses who, in a myriad of ways that we explore, differ from the norms of "typical" college students who were prevalent in the days when the disciplines of rhetoric and composition and writing across the curriculum were being originally formulated, and which prevail across the board in our institutions of higher education. For one thing, almost none of them are white, so to some extent this is an exploration of going to college while Brown, Black, or Asian. But our primary focus will be on their language performances and affiliations, the way in which their language identities are negotiated, and the ways in which the students' various language goals and performances may both develop from and help to form transnational experiences.

Students, that is, are the best experts on their language practices, experiences, proficiencies, and identities, but they often need a space in which they can reflect on what are, for them, often routine activities. That such mundane conversations which cross supposed linguistic and national boundaries are of interest to researchers comes as a surprise to some of our students, who find that linguistic identity is less a source of either anxiety or pride than monolingual speakers, looking at it from the outside, might expect. The students do not necessarily see their other languages as sources of weakness, but they don't necessarily see them as sources of academic strength, either, unless prompted.

In the pages that follow we examine how college students on two campuses conceptualize and articulate their own language identities, based on assigned language narratives, on short stories and their associated commentaries, on surveys and in interviews, and in instructor reflections. In their writings, students negotiate between the linguistic identities that are imposed upon them because of their skin color, educational background, perceived geographical origin, immigration status, and the many other cues that are used to "minoritize" them, and the linguistic identities which they actively construct and perform. Our textual analysis draws upon multiple disciplinary discourses of language and identity, including theories of critical pedagogy, of New Literacies, of translingual agency in rhetoric and composition, of code meshing and other translingual practices in applied linguistics, of language identities in second language writing, and on ueer and feminist theories. We examine the rhetorical and performative moves through which students structure relationships with particular language identities, attitudes, ambitions, goals, and visions of future use of English and other languages.

We report on three separate but related studies of translingual practices among two groups of students on two different U.S. college campuses in the northeast of the United States. Chapters 2, 4, 9, and 10 exploring the linguistic affiliations and practices of students on a public urban university campus which we will name Urban College, examine translingual practices within a broad umbrella of "Englishes," with emphases on post-colonial native English speakers and on African-American Vernacular Englishes. Chapters 2, 6 and 13 focus on two distinct groups of 
"international" students on the campus of a public research university, which we will name State University: 1) first-year undergraduates and 2) graduate students. Despite their cultural and experiential differences, all three groups of students may find themselves marked as outsiders within U.S. language practices that stress a limited definition of "standard English." Using similar methodologies, both projects began from a simple premise: ask the students how they negotiate their language identities on a day-to-day basis, and in their academic work, and examine what they show us when they do it. We seek to enter into their subjective linguistic world, by trying to create spaces in which students can speak or write, where they can use their languages and/or language varieties as a person who inhabits multiple language communities and where thinking or speaking or writing calls all the time - not just when they are consciously playing or performing - for the integrated use of their full linguistic repertoire, even if, as is almost always the case, the final product is recognizable as being "in" a single language. But what, exactly, do we mean by "in"? In the following sections, we explore this question in detail.

\section{Translingual/Transnational Spaces}

Translingual practices and transnational connections are frequent topics of investigation today in a variety of disciplines and settings. The translingual approach (Horner et al., 2011) has drawn increasing interest among scholars in writing studies (e.g. Canagarajah, 2013; Horner \& Tetrault, 2017; Bawarshi, Guerra, Horner and Lu, 2016; Lee, 2017), connected with parallel developments in TESOL (Jain, 2014) and applied linguistics (Garcia, 2009; Kubota, 2014); and also elicited some controversy, especially in second language writing (Matsuda, 2014; Atkinson et. al., 2015). Transnational issues, meanwhile, have illuminated a number of fields, ranging from the origins of the term in anthropology (Duany, 2008) and sociology (Levitt \& Jaworsky, 2007) to, more recently, Writing Program Administration (Martins, 2014); TESOL (Solano-Campos, 2014); composition studies (Donahue, 2009); and WAC/WID (Zenger, Haviland, \& Mullin, 2013), and mobility studies (e.g. Blommaert \& Horner, 2017). But these phenomena are often discussed in separation from each other, as though translingual practices and transnational connections were independent entities. Our approach, by contrast, explores the intersections between translingual and transnational practices. We move now to considering in more detail our terms of engagement for exploring these intersections.

\section{From Translingualism to Translinguality}

Viewing differences not as a problem but as a resource, the translingual approach promises to revitalize the teaching of writing and language. By addressing how language norms are actually heterogeneous, fluid, and negotiable, a translingual approach directly counters demands that writers must conform to fixed, uniform standards.

(Horner et al., 2011, p. 306)

Students and their instructors - who, as a group, may be more monolingual than the students whose linguistic practices we explore here-often approach translingualism from very different 
starting points. For monolingual instructors, it may well be that a "translingual approach" is a pedagogical aspiration, or a state of consciousness that they may someday be able to acquire by being open to otherness within language.

For our students, though, translinguality is not somewhere that they have to go, but rather somewhere that they already are, a place that they already inhabit every time they speak and each time they engage in reading and writing practices. They already live and embody translinguality, an often-unconscious state that many of them may not think about much, and that they may never have regarded as important until challenged in a course, when the instructor recast language difference, which they had thought of as negative or at best neutral, as, instead, a potential source of positive strength. Whether the students really come to think of it differently or whether they are just trying to please the instructor by saying so is another question, of course.

So we begin in a somewhat opaque and sometimes disputed theoretical territory of a translingual approach to language difference, and then make a turn simultaneously toward the concrete external conditions and toward the subjective reality of each student. Our various surveys, interviews, and analyses of student writing will help us to do so. For our readers, who may range from experienced researchers in translingual theories and approaches, to those who have not previously fully engaged in these scholarly conversations, we aim for rigorous analysis without getting lost in the theoretical weeds. Translingualism has deep roots in post-structuralism, postcolonial theory, multicompetence theory and other aspects of applied linguistics and second language study, which we will explore as needed. But our approach to translinguality - an existing condition rather than an ideology (that would be translingualism) — is better described as:

- a routine practice, implicated in every act of reading, writing, speaking, or listening, even when not consciously visible

- $\quad$ something that can be played with and/or performed consciously, exploring the echoes when languages bounce off each other, or blend together to create new language practices.

- a way of thinking about language and especially about language difference. It is here that translinguality morphs, perhaps, into an aspirational ideology of translingualism, a pedagogical consciousness mostly not yet achieved and difficult of access.

Translingual approaches toward language difference in writing are an important current topic in the discipline of rhetoric and composition, in second language writing and second language acquisition, in applied linguistics, and in various allied disciplines. Numerous panels at recent conferences in all these fields and in their publications testify to the interest-sometimes a somewhat controversial interest - in the subject. In this volume we will attempt to engage a nexus of theory and practice, asking how a rather theoretically complex concept can be applied in concrete situations - or at least attempts are made to do so. As a preliminary definition of a translingual approach to language difference, or to an ideology of translingualism, or, (we will argue) best of all, to the existing, routine, and inescapable condition of translinguality, here are three important translingual assumptions about language:

- Languages are not distinct entities, either at the macro-level of societal practices or at the micro-level of the individual user. Rather, they intersect, interact, and interpenetrate. 
- Students learn things in different languages, know things in different languages, and remember things in different languages.

- Teaching language or any aspect of it (writing, reading, speaking, listening) to translingual learners will benefit from affirming and encouraging students' continuing productive reliance on all their linguistic resources.

- Sometimes these ideas are referred to in rhetoric and composition as "the translingual approach" or "the translingual turn," but we are really articulating multiple approaches toward language difference. There seems to be a tension-perhaps a productive one, but one that should be acknowledged - between

O translingualism as a theoretical research framework, which can used to explain the relation of languages to each other, or to undermine traditional beliefs about the bright lines between languages

- translingualism as a pedagogical framework which is essential for writing instructors to incorporate into their models of instruction and especially of assessment

- translingualism as subject matter for students to understand and practice, sometimes in cross-cultural and cross-linguistic interchanges with students of different language backgrounds, sometimes in exploring their own linguistic repertoires in code-meshing experiments, etc.

- translingualism as a goal to be approached through a careful cultivation of an attitude toward language difference

- translingualism as simply a condition that exists, more or less unconsciously but continually exerting influence, every minute of every day when a speaker of more than one language or language variety reads, writes, speaks, or listens.

In this volume, rather than exploring these varying approaches to translingualism as such, we, rather write of translinguality. Of course, there is no such thing as a translinguality that is neutral in terms of post-colonial and racial power relations, or that is not situated in relation to existing ideologies of monolingualism, and so even as we assert that translinguality is everywhere, already operating in invisible and unconscious ways, the following chapters still must always inquire: why translinguality? whose translinguality? what kind of translinguality? for what purpose and where?

In this book, we conceive our task as that of making translinguality visible, by focusing on our students' experiences, as manifested in their writing and in their reported language experiences. Many students have got the message that in U.S. culture at large their non-English languages are not valued, and in fact are often regarded as a handicap to the speakers themselves and even as a provocation to the unconscious English-only ideology which pervades many aspects of U.S. society including academia, and which many of our students have therefore come to internalize. Students are not necessarily eager make use of their non-English languages in academic contexts, because they have always been told that English is the only way. Indeed, students who are immigrants, and/or whose language backgrounds include minoritized varieties of English, are sometimes the most vehement defenders of "Standard English"-or, as we write here, because it foregrounds its implication in structures of power, Standardized English-because they have worked very hard to acquire it and sometimes consider themselves to have arrived in a linguistic space where Standardized English is all that they need to use. It takes a process not only of 
education but of self-examination and a questioning of cultural boundaries for students to see, first, that they are already living in a translingual space in both their daily and their academic lives, and second, that this is potentially a good and useful thing for their own self-expression and for a re-valuation of language difference in the culture of academia and beyond. Translingual pedagogies create spaces where students tell their linguistic stories, implicitly or explicitly, rather than teaching them to stuff themselves into ill-fitting boxes. It can teach them about communication, not perfection. They can multiply their linguistic performances, rather than narrowing them down.

\section{Transnationality and Superdiversity}

Transnational identities - memberships or affiliations with multiple national communities — are increasingly common across the globe, even "the norm, rather than the exception" (Levitt \& Jaworsky, 2007, p. 146). National boundaries, however, continue to play significant administrative roles in our academic institutions, in terms of tuition structures, visa statuses and placement into English Language Learner (ELL)/English as a Second Language (ESL) and composition classes, and yet these bureaucratic categories fail to capture the complex nature of our students' lived identities. Ahmad and Nero (2011) argue that "Internal migrations and interaction of diverse peoples coupled with the transnational nature of twenty-first-century populations make for multiple homes and identities - real, imagined, claimed, and fluid. By extension, home languages can be real, imagined, claimed (or even rejected), and fluid but never static or monodimensional" (p. 73). The $20^{\text {th }}$ and $21^{\text {st }}$ centuries have been periods of immense, continual movement of people, ideas, currency, items and practices, back and forth between different nation states, but our academic institutions have been slow to keep up.

College students at both the undergraduate and graduate level are often members of transnational communities, even when what we see mostly is how they are enmeshed in their local ties. No matter what their citizenship status-U.S. citizen by birthright or naturalization; permanent resident, F-1 visa holder - many of our students live in a world in which their behaviors, their stuff, their food, their money, connects them to one or more nations and communities outside the United States. However, these connections often disappear behind the assumptions that instructors make in the college classroom: assumptions of the primacy of American English, and of the inadequacy of other languages and other varieties of English in our students' academic lives - including an assumption that students with other language affiliations will only use English as a "school language."

Yet despite institutional efforts to maintain these categories — standardized English, English as a Second Language, "international student" — as destinations but never as points of embarkation, students and faculty cross and re-cross, transgress, transcribe, translate, and transform these boundaries every day through their language work. Therefore we need to ask the question, "what does transnationality mean for language work in our classrooms and other institutional spaces?"

We have defined our expanded sense of translinguality - distinct from the ideology of translingualism - as both an everyday, pervasive phenomenon, a routine workhorse, and yet also as potentially a sophisticated tool for self-conscious expression of complex language identities. Transnationality is similarly approached both as a conscious claim or performance of identity 
and as also a largely unconscious immersion in cultural traces, connections, and memories, often mediated by the ongoing use of a minoritized language in a particular displaced setting.

\section{Trans- and transnationality}

As we have shown above, conversations about translinguality are well established in Composition Studies, and the field is now turning to considerations of transnationality, and how students' language practices are implicated by students' complex inter- and trans-national affiliations. Blommaert and Horner (2017) characterizes, for perhaps one of the first times in Composition Studies, our students' lives as full of movement without a necessary singular endpoint, which is what our narratives of immigration and language acquisition have tended to emphasize: movement towards a goal of linguistic assimilation. Horner argues,

...just as academic literacy researchers' efforts to accommodate students marked by the ideology of monolingualism as linguistically 'different' are now leading to challenges to notions of difference (and sameness) in language, what began with studies of the increasing mobility of students, IHEs, and knowledge as a feature distinguishing contemporary forms of these from the norm is now leading to recognition of the susceptibility of all knowledge to transformation through the process of its mobilization and to an alternative sense of mobility, now seen not as a new phenomenon distinguishing some learners, knowledge, and IHEs from others but as an inevitable feature of all these. (2017, p. 5).

With this idea of total movement in mind, we will move to consider the "trans-" part of transnational and translingual, and see what considerations of "trans" from Queer Studies afford us.

As a prefix, trans- is in common usage; as a theoretical space, trans- is relatively new in Applied Linguistics and Composition Studies. The Oxford English Dictionary's definition of trans-, the prefix, demonstrates the movement that is inherent in its use: "across, through, over, to or on the other side of, beyond, outside of, from one place, person, thing, or state to another" (Trans-, 2019). The aspects of this meaning that we would like to emphasize here are those where transrefers to a process of becoming and of crossing from one space to another. As a metaphor, transis inherently spatial. Trans- also connotes a lack of stability: settling at an end point of the crossing is less important, when we use words beginning with trans-, than the movement between points or spaces or times. As such, it can be thought of connoting disruption: its emphasis on movement is inherently destabilizing.

Perhaps the most culturally salient trans- at this moment in time is transgender: an identity performance in which an individual locates themselves outside and between traditional gender binaries, e.g. woman/man, girl/boy. Because of the frontier work being undertaken in transgender studies, we turn to the work with "trans-" being done in that field in order to expand our understanding of what "trans-" might bring to "translingualism" and "transnationalism" as theoretical constructs and descriptions of lived experience. 
Writing about the relationship between "transgender" and Queer Studies, Stryker (2004) suggests that the field of transgender studies "offers to queer theory a critique that is becoming a point of departure for a lively conversation, involving many speakers from many locations, about the mutability and specificity of human lives and loves. There remains in that emerging dialogue a radical queer potential to realize" (p. 215). The developing interest in and emphasis on translingualism in Composition Studies and Applied Linguistics, and transnationalism in Sociology (etcetera) suggest to us that these fields are also seeking a mechanism for such critique: one that recenters the conversation away from traditional ideologies of language and nation, towards the possibility of inhabiting intersecting and mutually constitutive spaces at the same time. Trans- focuses on change and individual experience, rather than asking —or requiring - individuals to conform to linguistic and national categories that may not be relevant to their experiences. Thus, we see trans- as similarly offering a critique to traditional concepts of linguistic and national identity as they are embedded in our terminology, such as multilingual, multinational, plurilingual, ESL/SLW, generation 1.5, immigrant, etc. Trans- theory can help us see that critique and reorient our focus to the spaces between nations and languages as places where many of our students spend most of their time.

To pursue this re-conception of our categories of language identity and national identity via consideration of what trans- means, again, we consider Stryker, Currah and Moore's (2008) articulation of "trans-" as a prefix, and as such its "implicit relationality," and therefore its implications for its possible suffixes. Their focus is on -gender, but their analysis also applies to other suffixes, in which list they include "-national, -racial, -generational, -genic, -species," to which we would, of course, add "-lingual." Stryker, Currah and Moore (2008) describe what the prefix of trans- does in the two following passages, drawing attention to the connections and the movement implied by trans-, :

- ... neither "-gender" or othe other suffixes of "trans-" can be understood in isolation - ... the lines implied by the very conception of "trans-" are moving targets, simultaneously composed of multiple determinants. "Transing," in short, is a practice that takes place within, as well as across or between, gendered spaces. It is a practice that assembles gender into contingent structures of association with other attributes of bodily being, and that allows for their reassembly. Transing can function as a disciplinary tool [a tool used to discipline individuals - hmr] when the stigma associated with the lack or loss of gender status threatens social unintelligibility, coercive normalization, or even bodily extermination. It can also function as an escape vector, line of flight, or pathway toward liberation. (p. 13)

- "Trans-" thus becomes the capillary space of connection and circulation between the macro- and micro-political registers through which the lives of bodies become enmeshed in the lives of nations, states, and capital-formations. (p. 14)

Of the many pieces of the conceptual frame established by Stryker, Currah and Moore (2008) in these two passages, we focus on their description of "transing" as a practice that takes place within spaces and networks of affiliation, and within which "structures of association" are contingent, and in which transing can also be used "at" individuals to keep them within their assigned identity spaces, or, more importantly for our work in this book, in which transing "function[s] as an escape vector, line of flight, or pathway toward liberation" (p. 13). And finally, we want to emphasize their description of "trans" as "the capillary space of connection 
and circulation between ... macro- and micro-political registers" (p. 14). Since languages and nations are ideological constructions - status as a language, rather than a dialect, for instance, is intimately connected with nationhood in the adage, popularized by Max Weinrich: "a language is a dialect with an army and a navy" - we want to emphasize the importance the political and social implications of transing as it challenges our conceptions of the boundaries of "language" and "nation."

Levitt \& Jaworsky (2007) write, in their definition of transnationalism, that Basch et al. (1994, p. 6) initially defined transnationalism as 'the processes by which immigrants forge and sustain multi-stranded social relations that link together their societies of origin and settlement.' More recent scholarship understands transnational migration as taking place within fluid social spaces that are constantly reworked through migrants' simultaneous embeddedness in more than one society (Levitt \& Glick Schiller, 2004; Pries, 2005; Smith, 2005). These arenas are multi-layered and multi-sited, including not just the home and host countries but other sites around the world that connect migrants to their conationals and coreligionists. (p. 131)

Again, this definition is conceptually contiguous with the theory of "trans-" outlined above: transnationalism is relational and enacted in the process of creating and maintaining relations between people; the spaces in which transnational migration occurs are "fluid" and "constantly reworked." To be transnational, as this definition indicates, is to occupy a dynamic space which is defined by acts of affiliation and performance; identity assignments based on national categories will necessarily be unable to capture the fluidity of the identities formed around processes of transnationals" "simultaneous embeddedness." What this definition also makes clear is that transnationalism is as much a set of connections between people as it is between geographical spaces, which connects to the definition of identity offered by Tabouret-Keller \& LePage (1985) and West (1992): people affiliate themselves with social groups through "acts of identity," driven by desire for these affiliations, these connections. We can see translingual and transnational identities emerge by what people do - how they use language, how they describe and claim their national affiliations.

Of the students participating in the studies presented here, the international students whose stories we narrate in Chapters 2, 6 and 13 of this book may seem, at first glance, to more easily fit the paradigm of transnational students. Indeed, by definition, "international" students are in a liminal situation, where their physical location on U.S. campuses is only part of the story of their language practices and personal/national identities. One variable is student aspirations: some students will complete their degrees (or not) and return to their countries of origin; others will attempt to stay in the United States or move to some other country, and such desires have important relevance both to how students regard the relation between their physical location and their sometimes-shifting notions of "home," and also to how they think about the relation between English as (at minimum) the medium of instruction and their other language(s).

"International" students thus cannot escape situating themselves (and being situated institutionally) on a continuum of transnational and translingual practices: they remain connected, to varying degrees and through different modalities, to their home countries, and yet must also establish a successful relation, of one kind or another, with their U.S. institution, its 
on-campus community, and the larger host culture. We will consider the status of "international" students as transnational sojourners in more detail in Chapter 6 and 13.

In Chapters 2, 4 and 9, the students are often U.S. citizens and permanent residents, but this does not mean that they are not transnationally connected. On the contrary, Urban College, the site of this study, is a campus with a high percentage of immigrants and children of immigrants, where a plurality, but not majority of students identify as "native English speakers," and where multiple Englishes, especially a continuum of African American and Caribbean Englishes, further complicate students' language backgrounds and transnational identity commitments. These students are undoubtedly "Americans," yet they maintain strong connections with other nation states; their continuing transnational connections have important implications for our study of their languaging. In our writing samples, students at Urban College explore what Glick Schiller (2003) describes as transnational "ways of being," and "ways of belonging," the social relations and practices that form transnational identities and "a conscious connection to a particular group" (Levitt and Jaworsky, 2007, p. 133). For example, we will meet a man who was born in the United States. but who maintains close familial and loose linguistic ties to Guyana; a woman born in Haiti who describes the ambivalence she feels at having left Haiti for the United States after the earthquake; and a man who emigrated to New York from Ghana with his family, and who resists the linguistic colonization that he experienced in Ghana, and which continues in the United States.

In these students' writing, we see how linguistic stories and (trans)national stories intersect, but do not always overlap. A user of a prestige variety of English may be, technically, "a foreigner." A U.S. citizen by birthright may consider their primary linguistic affiliation to be with a language other than English, or, indeed, with English and another language. We see in these our students' language work how the negotiation of linguistic identities intertwines with the negotiation of transnational identities.

The Urban College students depicted in Chapters 2, 4, 9 and 10 differ in another important way from the "international students" at State University depicted in Chapters 2, 6 and 13: the latter students are much more homogenous in terms of their national origin. Yet, as we will see, even though we can say that the students from State University who we discuss mostly "came from China," their language use, future ambitions, level of sophistication in regards to their disciplines, familiarity with U.S. culture all vary widely. At Urban College, the population is better described as superdiverse, defined as the "dynamic interplay of variables among an increased number of new, small and scattered, multiple-origin, transnationally connected, socioeconomically differentiated and legally stratified immigrants" (Vertovec 2007, p.1024).

Blommaert \& Rampton (2012) observe that super-diversity is characterized by a tremendous increase in the categories of migrants, not only in terms of nationality, ethnicity, language, and religion, but also in terms of motives, patterns and itineraries of migration, processes of insertion into the labour and housing markets of the host societies, and so on. The predictability of the category of 'migrant' and of his/her sociocultural features has disappeared." (p. 7).

In the absence of such "predictability," our methodology must arrive where we began: our only alternative is to Ask the Students. 


\section{Translingual Identities, Transnational Realities in the U.S. College Classroom}

We have offered, in this introductory chapter, our expanded sense of translinguality (as distinct from the ideology of translingualism) as both an everyday, pervasive phenomenon, a routine workhorse, and also potentially a sophisticated tool for self-conscious expression of complex language identities. We have presented, as well, a view of transnational identity and the ways in which it intersects with students' language backgrounds. And we offer an analytical framework based on the prefix trans-, which brings translinguality and transnationality together, and offers us a way forward in our consideration of how these phenomena are implicated and enacted in our classrooms. In the chapters that follow, we will detail and deepen these preliminary definitions by examining the ways in which our students, in their writings, in response to assignments that invite them to explore, to claim, and to create identities for themselves that may differ from those that have been imposed on them by cultures both in the U.S. and elsewhere.

We will also explore, more briefly, our own linguistic and national identities, in Chapters 3, 5 and 7, in three reflective essays from our perspectives as educators, language students ourselves, and language users, exploring our linguistic, national, and racial perspectives and privileges. It would be unethical to pretend to stand outside the struggles and triumphs of identity that or students put forward in their writings, as though we are somehow we were separate from that process, somehow already secure and fixed in our own identities. In Chapter 7, Jonathan, a "native" English speaker abroad struggles to learn Spanish, and finds that it's hard to miss that people have English on their minds, which heightens his sense of his own language identity, sometimes in uncomfortable ways. In Chapter 3, Heather, an immigrant to the United States, but one with white skin and a who speaks a high-prestige variety of English, discusses the (in)visibility of difference, and its impact on her teaching practice at a majority-minority institution. In Chapter 5, Nela, a child of immigrants raised in a translingual environment explores a translingual identity as a right, a cosmopolitan sensibility, a means of negotiating difference and creating meaning, as well as a creative force, one that informs her critical pedagogy teaching practices in a graduate program that supports translingual students at a state university.

Chapter 2, "Everyday Translinguality: We Meet Our Students" introduces the students from Urban College and State University in the educational contexts where we encounter them. Their language narratives reveal how students conceive their language identities based on their description of multiple contexts, codes, dialects, modes, and purposes. These student texts explore language identity as a dynamic textual negotiation between contextual imposed identities (including that of "international student") and claimed identities mediated through student agency as writers (Varghese et. al., 2005). The chapter examines the rhetorical moves through which students structure relationships with particular language identities, attitudes, ambitions, goals, and visions of future use of English and other languages. While these identities are somewhat different depending on whether the student is a U.S. resident or citizen or an international student, and depending on undergraduate or graduate status, each student had easily described a unique location in a matrix of interlocking languages. Their translingual identities, their infinite variations on the theme of being inside, out of, between, and around languages, are 
the subject of the brief sketches that we include, a combination of what they wrote in their papers and the details that they added in interviews and conversations with their instructor. Excerpts from interviews with the graduate students from State University round out the chapter and our brief introductions to the students whose translingual transnational lives we explore here.

Chapters 4 and 8 examine the challenges inherent in the effort to create a college classroom that engages translingual/transnational issues. "Transing Language Identity" argues that identity is the issue too often left out of even progressive approaches to writing pedagogy, and explores what a translingual and transnational language identity would look like, as well as pedagogies that center these translingual, transnational identity formations in our classrooms. "Transing Pedagogy" focuses on the faculty perspective of transing, considering how can we create assignments and classroom spaces and practices that invite students to explore their translingual and transnational identities, and what a trans- pedagogical methodology and orientation might look like.

In Chapter 6 and Chapter 13, we explore, in depth, ways of being an international student at State University, a large, research-intensive land-grant university in the Northeast. Chapter 6 focuses on how international students perform their linguistic affiliations over the arc of a semester. Five of the students whose identity performance we explore are in their second semester in an English for Academic Purposes sequence of courses at State University; two of them are graduate students studying in $\mathrm{PhD}$ programs at that institution. We discuss these students' biographical essays and literacy narratives, and, for the graduate students, interview responses, to consider the emergent linguistic affiliations that they establish during their degree programs at State University. In Chapter 13, we focus on interview responses from three graduate students, showing how students who are able to establish meaningful intersections between disciplinary discourses and everyday Englishes are able to establish translingual, transnational identities in ways that are not well-known in the international graduate student literature. Further, we contextualize these interview responses in the broader landscape of academic support at State University, using reflections from Nela, the director of the Graduate Academic Support Program (GASP) at that institution.

“Translanguaging, Performance and the Art of Negotiation," Chapter 9, explores translanguaging in student writing, considering what kinds of writing assignments might encourage translingual writing among students, and what kinds of philosophical approaches to these translingual assignments instructors might best adopt. The chapter begins by discussing the kinds of translanguaging that students at Urban College do on a regular basis, and some reasons behind this translanguaging, then moves on to discussing how translingual writing can be incorporated into core pedagogies in the classroom — including formal assignments considering the kinds of assignments that might give students space to perform translingually without requiring them to "out" themselves as translingual. The last part of the chapter explores the work of specific students, all from different linguistic backgrounds, but who are all adept translingual writers though their adeptness comes from different places.

The translingual turn in composition theory is partly a result of increasing engagement in scholarly alliance with other disciplines such as TESOL, applied linguistics, and second language acquisition. Chapter 10, "Reading Between Languages: Translingual Economies of 
Literacy" continues that dialogue by asking how this translingual turn might affect the way in which we apply our research to questions of reading as well as writing. What might the literature on second language reading have to contribute to our attempts to articulate a translingual approach to reading, one that would account for bi-directional flows of language, for interactional exchanges of meaning, for what is called here translingual economies of literacy? In order to anchor these theoretical discussions in actual examples, two case studies are interspersed, one Urban College student and one instructor, Jonathan, who discusses his own experience of translingual reading.

Chapter 11, "Translinguality, Grammatical Literacy, and a Pedagogy of Naming" takes as its starting point the end of Canagarajah's 2006 essay 'in which he argues for the incorporation of World Englishes into the discourse of composition, and challenges students to use their 'preferred varieties' of English alongside the dominant ones in 'rhetorically strategic ways' (2006a, p. 598-599). Picking up where Canagarajah left off, this chapter explores a pedagogical approach which moves the 'pluralization of English' into the 'deep structure' of grammar.' Using a grammar course as a case study, this chapter outlines an approach to teaching at the sentence-level that embraces linguistic pluralism and anti-racist attitudes to language.

Chapter 12, "Human Rights, Language Policies, and Language Identity: A Pedagogical Approach" explores how employing a language rights as well as a linguistic human rights framework can provide a critical lens for understanding translingual pedagogical practices and spaces as a rights based imperative. It also aims to underscore the obligations that educational institutions have to promote and protect the linguistic rights and identities of their students as well as recognize and support the use of their languages in the academy. These frameworks can offer an understanding of the limitations of current language policies and programs in which students in the "global university" are expected to assimilate, "mainstream" and work exclusively in the language and identity of the dominant group. This chapter examines why the implementation of language and linguistic human rights is central to cultivating and protecting translingual practices and spaces, embracing inclusion as well as a cosmopolitan sensibility.

Our conclusion, "Composing Translingually and Transnationally: Blurring Borders Through Languaging," revisits the role of translinguality and transnationality in the formation of language identity, and the consequences for pedagogy in U.S. writing and language classrooms. What does translingual mean for English native speakers, who may well speak several varieties of English, and use "a broad and diverse repertoire of language resources"? What does it mean for our pedagogy if we move a consideration of students' transnational experiences from the margins to the center of our work in the classroom? How does translanguaging construct an audience? What do we get if we teach students a more nuanced perspective on native-speaker/non-native speaker status? What do we gain-pedagogically, experientially, and in research-from making translinguality and transnationality visible? 